\title{
COMPUTATIONAL MODELLING OF TYRES CONSIDERING OPERATING AND SAFETY REQUIREMENTS
}

This contribution deals with the structural concept of tyres considering operating and safety aspects. Results obtained from experimental modelling of tyres considering operating and functional aspects are an essential condition of generation of "correct" computational models of tyres. Achievement of harmony between all requirements on the tyre and resulting demands on safety which would lead, apart from other things, to an increase of the life of the tyre, is a topical issue of computing algorithms in tyre-manufacturing plants.

\section{Introduction}

The rapid development of automotive industry is evidenced by the production of a large variety of vehicles. New more powerful and more perfect road and off-road cars are placed on the market. Automobile manufacturers try to outstrip competitors by quality and quantity of products, whereby their priority is to meet all operating and safety requirements and, at the same time, to guarantee long life and reliability of the car, which is considered as a comprehensive dynamic system. All this is required in spite of the increasing speed of cars and customer requirements for comfort, ergonomics, etc. Light materials are used to reduce car weight and, consequently, operating costs.

The extensive development of cars and all transportation means cannot manage without predicting loading states by quick estimates. A combination is used of computational modelling as a supporting tool and the classical experimental approach. Computer aids should facilitate designers and development engineers drafting prototypes and models which are used for load tests of individual components as well as of whole automobiles.

Tyres are developed along with cars namely considering their design, material and safety. The reason for this is that tyres as the elements assuring good interaction between car and road must meet critical safety criteria at high speeds (the defect of a tyre on a highway at high speed has to be controllable and must not lead to fatal accidents). This is incidentally also a question of assigning the correct type of a tyre to a car and to its operating conditions (tyres only for road operation, for off-road, combined operation as well as for summer or winter conditions). This is why the use of computational modelling is applied also to the field of tyres (design modification - change of inclination angle of reinforcing fibres, number of reinforcing layers, materials of cords, etc.).
The work of the author over a long period of time is devoted to radial tyres for passenger motor cars and, particularly, to their computational modelling $[1,2]$.

In order to be able to adopt a comprehensive approach to the state of the art trend of computational modelling, it is necessary to have good knowledge of the function of wheels with tyres, different types of tyres, their design, structure, range of materials, operating conditions, characteristic behaviour at particular modes of loading and knowledge of more details and data. All these can be considered as input parameters absolutely necessary for computational modelling without which present modelling engineers cannot manage.

The present contribution deals with the structural concept of tyres considering operating and safety requirements.

For a comprehensive approach the functions of wheels with tyres are a primary issue.

\section{Functions of wheels with tyres}

The function of wheels with tyres is not only to align a car reliably. As can be seen in more detail from Fig. 1 there are more requirements on tyres. The main operating requirements on car tyres are that car wheels should be as light as possible and, at the same time tough, statically and dynamically balanced.

The main requirements on tyres are, apart from other things, high wear resistance, optimal deformation characteristics, low rolling resistance, high operating life, etc. Wheels with tyres must meet particular functional requirements given by parameters of tyres which affect the running properties of the car, i.e. affect their dynamic behaviour (car manoeuvrability, stability, acceleration, deceleration, driving comfort, etc.).

\footnotetext{
* Jan Krmela

Department of Transport Means and Diagnostic, Jan Perner Transport Faculty, University of Pardubice, Czech Republic; E-mail: Jan.Krmela@upce.cz, Jan2.Krmela@post.cz
} 


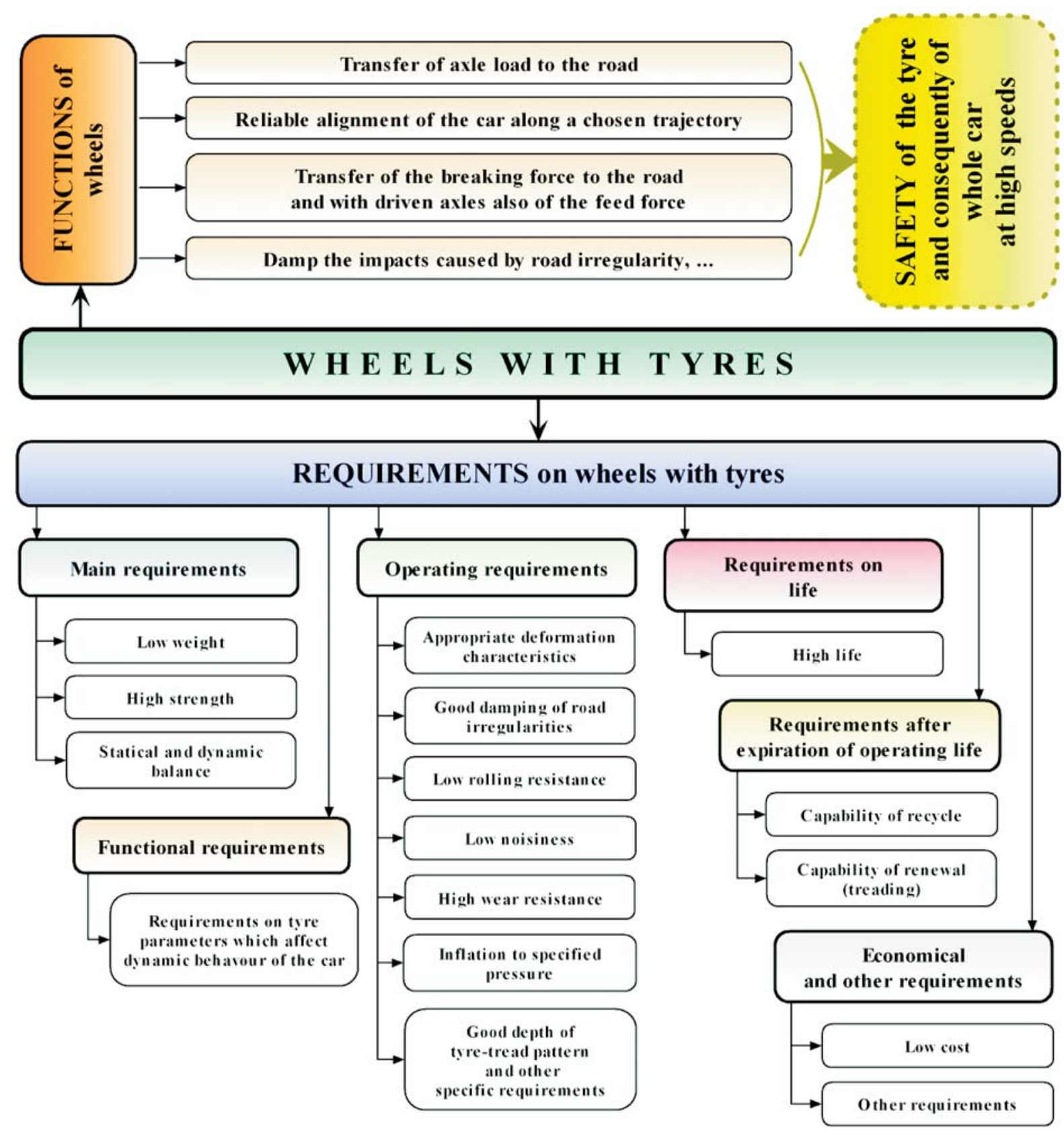

Fig. 1 Functions of wheels with tyres and requirements on them [2]

Further specific requirements on tyres, e.g. vehicles handling material in metalworks close to metallurgical furnaces where tyres are exposed to extremely high temperatures are as well as to sharp objects.

\section{Definition of a tyre}

Tyres as heterogeneous composite bodies can be defined from various viewpoints as shown in Fig. 2. From a geometrical point of view the tyre is an annulus, from the viewpoint of strength and flexibility it can be considered as a pressure vessel and with respect to the structure of individual parts of the tyre casing and respective different properties a tyre can be considered as a part with anisotropic properties. Furthermore, a tyre can be statically and dynamically loaded, which is given by the actual operating condition.

A specific requirement on tyres is safety at high speeds and the consequential measures aimed at preventing fatal road accidents. 


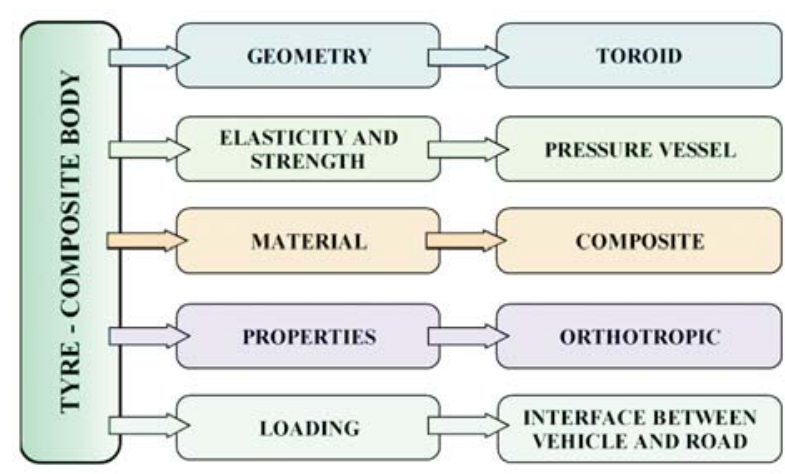

Fig. 2 Definition of tyre from various viewpoints [2]

\section{Tyres for high speeds from the viewpoint of safety}

Tyre safety is passive and active - see Fig. 3. Passive safety depends on the quality of the production of a tyre casing, the applied technology and used materials and in the case of computational modelling also on the accuracy of the performed calculations and appropriate choice of the computing algorithm.

Requirements on active safeness are particularly high running safety on various types of road surfaces, breakdown resistance, speed resistance and high life of materials used for the production of tyres, namely reinforcing materials.

The aim is to avoid fatal road accidents which might be caused by tyre casing defects either by neglecting operating conditions of tyres (depth of tyre tread pattern, tyre inflation pressure, use of inappropriate tyres with a different structure, etc.) or by bad vulcanization during the manufacturing process creating delaminations.

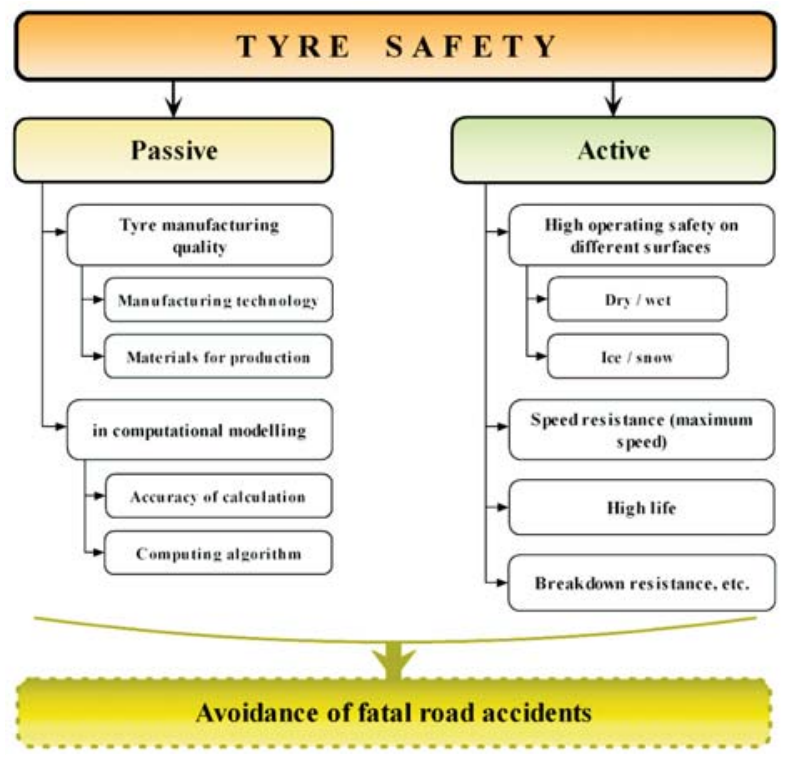

Fig. 3 Viewpoints of tyre safety [2]
For this reason tyres and wheels as a unit are modified from the structural point of view, particularly for special army vehicles where even a sudden drop of pressure does not put an end to the operating capability of the vehicle (system with a central collar providing circular indexing of the casing with respect to the wheel rim).

New features are introduced for high speeds, e.g. electronic systems which warn the drivers in the case a gradual drop of the tyre pressure or adjusting systems for inflation based on the temperature load of the tyre casing. Each manufacturer protects the results of his developments and patents considering them as private "know-how". Consequently, all new information is only very scarcely available.

The listing of various structural modifications would lie outside the scope of this contribution. Obviously this is an actual topic where the use of modern computational methods is advanced and purposeful.

Tyres are subject to internal and external effects which can more or less cause limit states leading to degradation processes (delamination, etc.).

During the operation of a vehicle combined loading of the tyre occurs both from a mechanical (statical, dynamic) and a temperature point of view (local heating in subzones, global heating in the tyre-tread area permeating into the tyre during breaking). Also this has to be considered in defining tyre safety at high speeds.

\section{Requirements on tyre life}

Tyres must resist during operating to surrounding effects, to negative effects of operation and to other effects, which could lead e.g. to delamination. Resistance to the following effects is considered:

- puncture - capability of tyre to resist puncture by sharp objects

- cut-through - capability of tyre (especially of the tread and sidewall) to resist contact with sharp objects

- breakdown - capability of tyre to resist damage during shortterm loading by concentrated forces

- fatigue - capability of tyre to resist material fatigue and defects in consequence of repeated loading cycles

- separation and delamination - capability of structural tyre components to maintain integrity of the system during operation

- humidity - tyre elements must be able to resist degradation by contact with water

- ozone influence - capability of tyre and of its components to resist degradation caused by ozone present in atmosphere

- temperature - tyre components must be able to resist high and low ambient temperatures and also consequences of contact with the road

- chemicals - capability of tyres and their components to resist degradation caused by chemicals (in winter - influence of salt solutions). 
Knowledge of the extent of resistance of tyres to various modes of loading and effects of the environment is gained from tests of strength and life - in other words from destructive tests (Fig. 4).

\section{Tests of tyres for computational models}

Computational modelling requires confirmation analyses combined with experiments. This is the reason why it is necessary to run not only tests of tyres as a whole, as shown in Fig. 4, but also tests of individual tyre casing components [3], purposely separated parts etc.

This is how an overview which structural modifications can lead to an increase of the level of safety criteria, increase of resistance, life etc. can be obtained.

Basic statical deformation characteristics of tyres can be obtained from a device called statical adhesor (Fig. 5), which is available to author. The statical adhesor also enables measurement of data from the contact surface under defined conditions, as presented in Fig. 5.

\section{Computational modelling of tyres}

If relevant results are obtained from experimental modelling of whole tyres and individual components and all input data are available, generation of computational models of the tyre casing can proceed [4]. On the basis of the author's long experience the FEM model of an actual radial tyre (Fig. 6) was generated which is "open" to different modes of loading and analyses assuming necessary input data are completed into the calculations.

\section{Conclusions}

This contribution deals only with a specific field which the computing engineer has to be well acquainted with from an operating and safety point of view and from the resulting requirements for tyre resistance. This is the only way how to obtain highly sophisticated computational models of tyres, naturally assuming knowledge of accurate material parameters of all parts of the tyre casing and of the other necessary data such as inputs of road characteristics, load, type of car, etc.

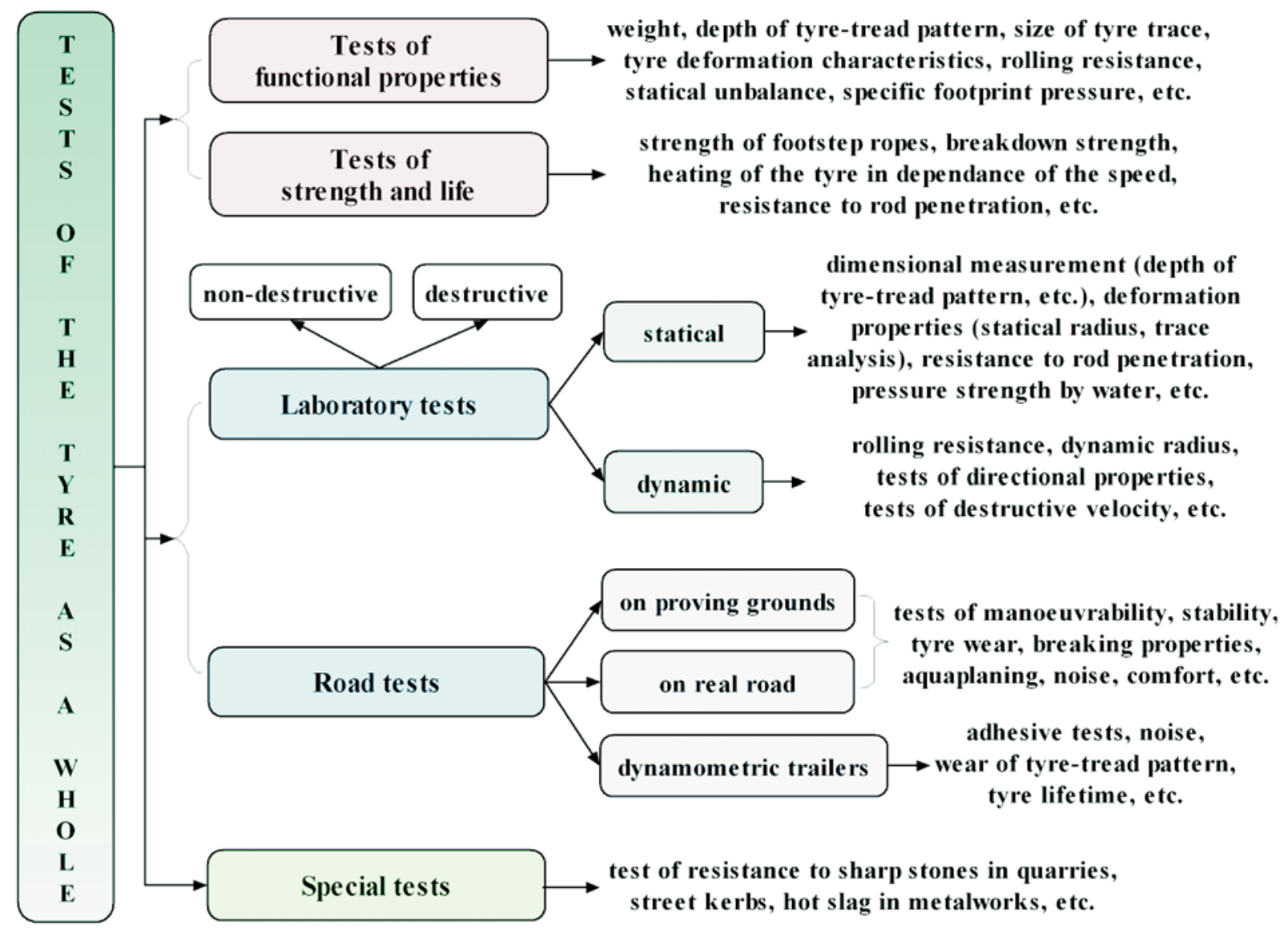

Fig. 4 Tests of the tyre as a whole [1] 


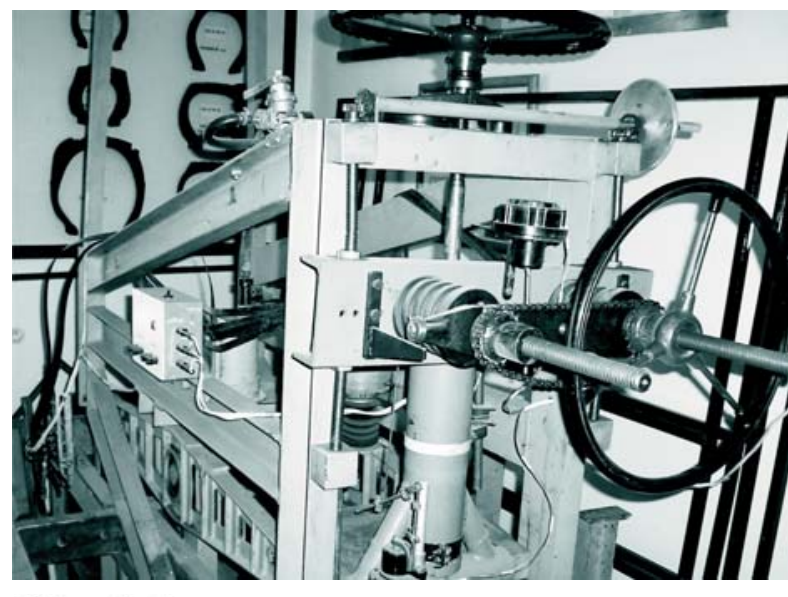

Data on the tyre:

$\checkmark$ radial deformation characteristics

$\checkmark$ size and shape of contact surface

$\checkmark$ distribution of contact pressure in contact surface

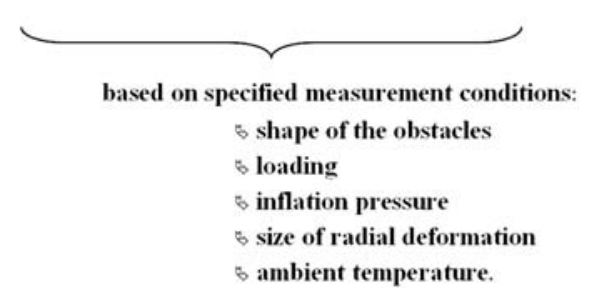

Fig. 5 Statical adhesor and measureable data of the tyre

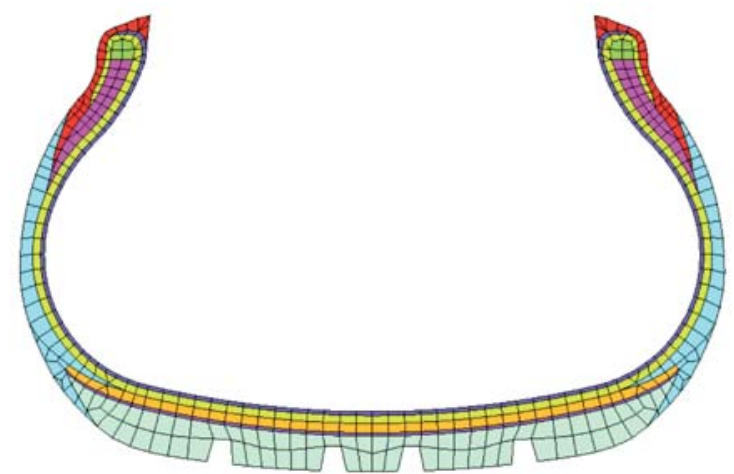

Fig. 6 Computational model "open" to further analyses (cross section)

Approach to the compiling of the computational models of the tyre shown in [2] can be applied also to the other construction types of the tyres, different sizes, etc.

\section{References}

[1] KRMELA, J.: Design of the Computational Three-Dimensional Model of the Radial-ply Tyre (in Czech), [Dissertation thesis], Ceska Trebova, Jan Perner Transport Faculty, University of Pardubice, Czech Republic, 2004, p. 226

[2] KRMELA, J.: Systems Approach to the Computational Modelling of Tyres - I. Part (in Czech), Monograph, Brno, Czech Republic, 2008, p. 102, ISBN 978-80-7399-365-8, Online: 〈http://www.tyre-fem.wz.cz〉

[3] KRMELA, J., PESLOVA, F., HAJDUCHOVA, L.: Composite with Elastomer's Matrix (in Czech), Material Engineering, University of Zilina, 3/2004, pp. 17-24, ISSN 1335-0803.

[4] KRMELA, J.: The Computational Modelling of Multi-Layer Composites' Materials (in Czech), Proc. of conference Dynamic Rigid and Deformable Bodies 2006, Usti nad Labem, Czech Republic, 2006, pp. 103-110, ISBN 80-7044-782-6.

[5] RUSNAKOVA, S. et al.: Assessment of Espi Technique for Detection of Vibration Behaviour of Composite Laminates, Proc. of 12th International conference on Problems of Material Engineering, Mechanics and Design, Jasna, Slovakia: 2007, CD-ROM - Full texts of paper, p. 3, ISBN 978-80-969728-0-7.

[6] KRMELA, J., HAJDUCHOVA, L., PESLOVA, F., JANICEK, P.: Composite Structures Used in Tyre, Proc. of $22^{\text {nd }}$ International Colloquium Advanced Manufacturing and Repair Technologies in Vehicle Industry, Poland, 2005, pp. 15-16, ISBN 80-8070-393-0. 